\title{
Multi-Model Intelligent Prediction of Pakistan Port Throughput under the Background of China-Pakistan Economic Corridor
}

\author{
Aimin Deng, Qian Ding
}

\begin{abstract}
China-Pakistan Economic Corridor is model project and flagship project of China's "One Belt One Road "initiative. The cooperation between China and Pakistan covers all levels of power, roads, ports, and even education. A large number of investment in infrastructure and industrial projects will greatly promote Pakistan economic development greatly, which will bring strong industrial development, transportation logistics and increase port throughput, so we carry out forecast analysis of Pakistan port throughput in order to provide relevant government enterprises with a valuable reference for decision-making. This paper uses three intelligent forecasting models: neural network model, logistic model and grey theory model to predict Pakistan's port throughput and container throughput in $2020,2025,2030$, and 2035. The forecast result data shows: in good times, economic trends by 2035. The optimistic high forecast results in port throughput reaching about 220 million tons and container throughput reaching 6.91 million TEU. On the contrary, when the economic trend is relatively weak, the low forecast result of Pakistan's port throughput is $\mathbf{1 1 3}$ million tons, and the container throughput is 2.89 million TEU.
\end{abstract}

Index Terms - grey theory model prediction, logistic model prediction, neural network model prediction, Pakistan port throughput.

\section{INTRODUCTION}

China-Pakistan Economic Corridor is the model project and flagship project of China's "One Belt One Road " initiative. Investment in a large number of infrastructure and industrial projects will greatly promote Pakistan economic development, increase GDP and improve cargo flow. Seaports are generally important to the country portal, because its throughput is generally positively correlated with GDP and cargo flow. Karachi Port, Qasim Port and Gwadar is the three major ports of Pakistan and Gwadar Port is continuous construction of China. After taking over in, Karachi Port and Qasim Port bear 96\% of the import and export cargo transportation volume. There is almost no inland water transportation in Pakistan. The power of port transportation comes from the flow of commodities brought about by international trade, including commodity import, export, re-import and re-export. Pakistan's import and export transportation mainly relies on sea transportation, and the

Aimin Deng, the School of Economics and Trade, Hunan University, Changsha, China

Qian Ding*, the School of Economics and Trade, Hunan University, Changsha, China total value of seaborne goods accounts for more than $84 \%$ of the total import and export value, which is currently stable at about $87 \%$.Since most of the imported commodities are commodities with lower price per unit weight, such as petroleum, chemicals, transportation equipment, etc., the cheaper shipping method is determined as the main import channel. In 2012, the total import and export weight of Pakistan reached 316,600 million tons. In 2017, the total import and export volume of Pakistan was 312.3 million tons. In order to meet the needs of future import and export of goods, Pakistan has invested a lot of money in port infrastructure, and its port construction rating has also been upgraded from 3.7 to 4.1 in the past. The International Monetary Fund approved Pakistan's US\$6.4 billion loan application for national construction, and Pakistan, through the strategic cooperation of the China-Pakistan Economic Corridor, in the development of energy, infrastructure, industrial parks and economic zones, and the development of Gwadar Port Cooperate in four areas to promote national construction. It is planned to add 10,000 megawatts of electricity to the national grid to meet future development needs and lay a solid foundation for industrial electricity use. Pakistan has signed the construction of two major highways with China, one is the Karachi-Lahore highway, and the other is the Kashgar-Gwadar highway connecting China and Pakistan, from Xin Jiang Province to Pakistan. It is planned to set up 4 to 5 locations in the country as pilot projects in industrial parks to promote regional economic development. This article believes that the construction of the China-Pakistan Economic Corridor will drive the growth of Pakistan's GDP, bring about strong industrial development and transportation logistics, and increase port throughput. The forecast and analysis of Pakistan's port throughput are carried out in order to provide a valuable reference for relevant government enterprises. Basis for decision-making.

\section{LITERATURE REVIEW AND RESEARCH METHODS}

\section{A. Literature review}

From the perspective of relevant domestic and foreign research, many scholars have done a lot of academic discussion on port throughput forecasting. For example, Zhang Lijun, Zhang Ping and others used the principal component analysis method to find that the regional GDP, the output value of the secondary industry, the output value of the tertiary industry, the railway freight route, and the total 
import and export volume have a positive impact on the port throughput, and the output value of the primary industry, road freight volume has a negative impact on port throughput. Xu Jianhua and Wang Dan analyzed the macro environment of Ningbo Port and Tianjin Port in China, and pointed out that economic development, improvement of people's living standards, scientific and technological progress, development of foreign trade, improvement of cross-strait relations, acceleration of urbanization, development of hinterland resources and promotion of throughput. Zhu Jian established a VAR model based on the gravity model of my country's coastal port cargo throughput, and used the data since the financial crisis as a sample to test the model. It is found that the RMB exchange rate, fixed investment in the transportation industry, and world economic conditions all have a greater impact on port traffic, while domestic economic conditions have no significant impact on port cargo throughput. Tomás Serebrisky, Bruce A. Blonigen, etc. used 10 years of panel data to return to 63 ports along the Latin American and Caribbean Sea, and found that port technical efficiency represented by terminal area, berth length and number of cranes has an impact on port economic development Plays a decisive role. Liu Yan and others used the grey system theory to study the throughput forecast of Huainan Port and pointed out that when making long-term and short-term forecasts, the GM $(1,1)$ model and Verhulst model should be changed to make the results more accurate. Rashed Y and Chen are using multiple models to compare and find that the seasonal ARIMA model is more realistic. Lubo et al. put forward a new idea for port throughput forecasting and established a port forecast model based on context changes. The purpose is to adjust the penalty coefficient to quickly adapt the model to the status quo when the port context changes. Through the throughput data of Dalian Port and Tianjin Port from 1980 to 2014, the model is compared with the SARIMA model, and it is concluded that the port throughput forecast model with changing circumstances is more realistic. At present, through regression models, the method of forecasting based on the influencing factors of port throughput is not completely applied due to influencing factors. At present, the main forecasting method is to analyze time series data and predict future throughput based on past throughput. From the aspect of data results, the fitting effect is better. But there are also disadvantages. This model cannot reflect the forecast of emergencies or port throughput that is still in its infancy stage, because ports in the infancy stage are still under construction, and the past throughput has little reference for the future. More forecasting requires planning and strategic insight, combined with expert forecasting methods to achieve better results.

\section{B. Research methods}

According to existing research, the main forecasting methods generally include time series method, regression analysis method, grey model forecasting method, neural network method and combination forecasting method. In actual forecasting, different methods are suitable for different situations due to their inherent forecasting logic and model limitations. However, a purely single model will be biased in the prediction behavior. Therefore, combining different prediction models, combining the predicted values with weights, and fusing the advantages of each model will make the prediction more scientific and referential .Therefore, this paper chooses to predict the throughput of Pakistan's ports with neural network prediction models, growth curve models, multivariate prediction vector error correction models and their combined models.

\section{Neural network prediction model}

Neural network model is a new information processing method, imitating the brain operation mode, by inputting multiple sets of data, performing non-linear processing, and outputting predicted values through its own continuous learning and testing. A neural network usually consists of three layers: input layer, hidden layer and output layer. The functional relationship between output and input of each hidden layer and output layer neuron is:

$$
\begin{gathered}
\mathrm{Ij}=\sum \mathrm{iWijOi} \\
\mathrm{Oj}=\operatorname{sigmod}(\mathrm{Il})=11+\mathrm{e}-\mathrm{Il}
\end{gathered}
$$

Among them, Wijrepresents the weight of the connection between neuron $\mathrm{i}$ and neuron $\mathrm{j}, \mathrm{Oj}$ represents the output of neuron $\mathrm{j}$, and sigmod is a special function used to map any real number to the $(0,1)$ interval.

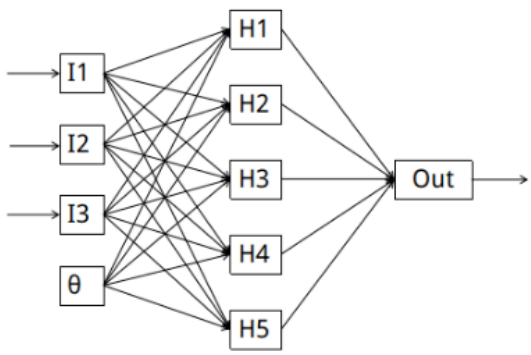

Figure 1. Schematic diagram of neural network prediction model

\section{Growth curve model}

Growth curve (also known as Logistic model) is a kind of growth curve, which belongs to the nonlinear model of time series model. It mainly describes the growth process of things that are in the upward development stage over time. The growth process has gone through three stages: slow start, rapid growth and slow growth and finally stabilized, which is in line with the logic and facts of the growth cycle of things. The throughput of Pakistan's ports is shown in Figure 2. It can be seen that due to port facilities and road-to-port connectivity, the growth phase of Pakistan's port throughput is between the initial period and the rapid growth period. The formula of the growth model is as follows:

$$
\begin{gathered}
\mathrm{Y}=1 /(1 / \mathrm{u}+(\mathrm{b} 0 *(\mathrm{~b} 1 * * \mathrm{t}))) \\
\text { or } \ln (1 / \mathrm{y}-1 / \mathrm{u})=\ln (\mathrm{b} 0)+(\ln (\mathrm{b} 1) * \mathrm{t})
\end{gathered}
$$

Among them, $\mathrm{u}, \mathrm{b} 0, \mathrm{~b} 1$ are parameters, and the independent variable $\mathrm{t}$ is time. The values corresponding to the three parameters can be calculated through calculation, so that $y$ can be predicted through time $t$. 


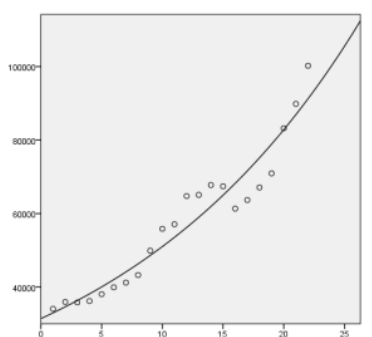

Figure 2 Time trend of Pakistan port throughput

\section{Grey prediction model}

The gray model is to establish a gray differential prediction model through a small amount of incomplete information, and make a fuzzy long-term description of the development of things. The essence of establishing the $\operatorname{GM}(1,1)$ model is to accumulate the original sequence once to make the generated sequence show a certain law, and then establish the first-order linear differential equation model to obtain the fitting curve to predict the system. The general form of the model is:

Let the original sequence:

$$
\mathrm{x}(0)=\{\mathrm{x}(0)(1), \mathrm{x}(0)(2), \cdots, \mathrm{x}(0)(\mathrm{n})\} \quad(1)
$$

Do an accumulation to generate:

$$
\begin{aligned}
& \mathrm{x}(1)=\{\mathrm{x}(1)(1), \mathrm{x}(1)(2), \cdots, \mathrm{x}(1)(\mathrm{n})\} \quad(2) \\
& \text { Where } X^{(1)}=\sum_{j=1}^{i} X^{(0)}(j) X^{(1)} \quad(\mathrm{i}=1,2, \cdots, \mathrm{n})
\end{aligned}
$$

For the first-order linear whitening differential

$$
\text { equation } \frac{d x^{(1)}}{d t}+a x^{(1)}=u
$$

Solve the parameters a, u using the least square method.

The gray prediction $\operatorname{GM}(1,1)$ model of $\mathrm{X}^{(1)}$

is $\hat{X}^{(1)}(k+1)=\left[X^{(0)}(1)-\frac{u}{a}\right] e^{-a k}+\frac{u}{a} \quad(\mathrm{k}=0,1,2, \cdots)$

After the calculation of $\hat{X}^{(1)}(k+1)$, the actual forecast value can be obtained $X^{(0)}(k+1)=\hat{X}^{(1)}(k+1)-\hat{X}^{(1)}(1)$.

\section{ModEL ESTIMATION AND RESUlT ANALYSIS}

\section{A. Pakistan port throughput forecast}

\section{Neural network prediction}

Using the neural network method to predict, take GDP denominated in constant US dollars in 2010, total import and export of goods, total population, and total household consumption denominated in constant US dollars in 2010 as covariates, and use port throughput from 1996 to 2017 The amount (thousand tons) is used for machine learning, and the final fitting results are as follows:

Table 1 Neuro predictive covariate index

\begin{tabular}{c|c|c|c|c}
\hline years & $\begin{array}{c}\text { Total } \\
\text { population } \\
(100 \text { million } \\
\text { people })\end{array}$ & $\begin{array}{c}\text { GDP (tens of } \\
\text { billions of } \\
\text { dollars) }\end{array}$ & $\begin{array}{c}\text { Import and } \\
\text { export of goods } \\
\text { and services } \\
(100 \text { million US } \\
\text { dollars })\end{array}$ & $\begin{array}{c}\text { Residents' final } \\
\text { consumption } \\
\text { expenditure (10 } \\
\text { billion US dollars) }\end{array}$ \\
\hline 1996 & 1.273 & 10.428 & 374.773 & 8.534 \\
\hline 1997 & 1.311 & 10.534 & 357.389 & 8.892 \\
\hline 1998 & 1.348 & 10.803 & 337.181 & 9.031 \\
\hline 1999 & 1.386 & 11.198 & 321.582 & 9.702 \\
\hline 2000 & 1.423 & 11.675 & 332.523 & 9.741 \\
\hline 2001 & 1.460 & 12.090 & 351.263 & 10.079 \\
\hline 2002 & 1.495 & 12.394 & 370.911 & 10.261 \\
\hline
\end{tabular}

\begin{tabular}{l|l|l|l|l}
\hline 2003 & 1.531 & 13.110 & 436.961 & 10.626 \\
\hline 2004 & 1.567 & 14.099 & 412.370 & 11.309 \\
\hline 2005 & 1.603 & 15.018 & 525.321 & 12.528 \\
\hline 2006 & 1.640 & 15.904 & 605.781 & 12.852 \\
\hline 2007 & 1.678 & 16.673 & 593.457 & 13.407 \\
\hline 2008 & 1.716 & 16.956 & 604.880 & 13.884 \\
\hline 2009 & 1.755 & 17.436 & 535.534 & 13.818 \\
\hline 2010 & 1.794 & 17.717 & 582.324 & 14.123 \\
\hline 2011 & 1.833 & 18.203 & 587.596 & 14.771 \\
\hline 2012 & 1.873 & 18.842 & 540.222 & 15.514 \\
\hline 2013 & 1.913 & 19.670 & 574.527 & 15.846 \\
\hline 2014 & 1.953 & 20.590 & 571.883 & 16.731 \\
\hline 2015 & 1.994 & 21.564 & 551.648 & 17.216 \\
\hline 2016 & 2.036 & 22.756 & 601.543 & 18.528 \\
\hline 2017 & 2.079 & 24.020 & 681.997 & 20.103 \\
\hline 2018 & 2.572 & 25.422 & 791.724 & 21.352 \\
\hline 2019 & 2.887 & 25.673 & 850.543 & 21.975 \\
\hline 2020 & 3.227 & 17.833 & 791.240 & 22.556 \\
\hline 2025 & 5.280 & 21.649 & 978.374 & 28.648 \\
\hline 2030 & 7.936 & 26.146 & 1231.514 & 36.534 \\
\hline 2035 & 11.207 & 31.427 & $1,566.897$ & 46.549 \\
\hline
\end{tabular}

Table 2 Pakistan port throughput (unit: 100,000 tons) forecast results

\begin{tabular}{l|c|c|c|c|c|c|c}
\hline years & $\begin{array}{c}\text { Port } \\
\text { throughp } \\
\text { ut } \\
(100,000 \\
\text { tons) }\end{array}$ & fitted value & Error ratio & years & $\begin{array}{c}\text { Port } \\
\text { throughpu } \\
\text { t } \\
(100,000)\end{array}$ & $\begin{array}{c}\text { fitted } \\
\text { value }\end{array}$ & Error ratio \\
\hline 1996 & 340.60 & 359.74 & $-5.62 \%$ & 2010 & 674.27 & 655.12 & $2.84 \%$ \\
\hline 1997 & 359.35 & 359.74 & $-0.11 \%$ & 2011 & 613.51 & 655.12 & $-6.78 \%$ \\
\hline 1998 & 357.98 & 359.74 & $-0.49 \%$ & 2012 & 636.90 & 655.19 & $-2.87 \%$ \\
\hline 1999 & 361.90 & 359.74 & $0.60 \%$ & 2013 & 671.01 & 709.41 & $-5.72 \%$ \\
\hline 2000 & 380.62 & 378.60 & $0.53 \%$ & 2014 & 709.41 & 709.41 & $0.00 \%$ \\
\hline 2001 & 399.18 & 412.03 & $-3.22 \%$ & 2015 & 832.18 & 709.41 & $14.75 \%$ \\
\hline 2002 & 412.03 & 412.03 & $0.00 \%$ & 2016 & 898.51 & 919.56 & $-2.34 \%$ \\
\hline 2003 & 432.65 & 421.31 & $2.62 \%$ & 2017 & 1002.40 & 950.26 & $5.20 \%$ \\
\hline 2004 & 498.94 & 498.94 & $0.00 \%$ & 2018 & & 987.74 & \\
\hline 2005 & 558.55 & 561.15 & $-0.47 \%$ & 2019 & & 989.19 & \\
\hline 2006 & 570.97 & 568.15 & $0.49 \%$ & 2020 & & 1021.29 & \\
\hline 2007 & 647.61 & 64812 & $-0.08 \%$ & 2025 & & 1040.38 & \\
\hline 2008 & 650.87 & 649.01 & $0.29 \%$ & 2030 & & 1042.85 & \\
\hline 2009 & 677.79 & 655.04 & $3.36 \%$ & 2035 & & 1136.93 & \\
\hline
\end{tabular}

It can be seen from the above table that the results of port throughput (100,000 tons) predicted by neural network, except for the abnormal value in 2015, the remaining basic error ratios are all below 6\%.Analyzing the port throughput in 2017 , the port throughput growth in 2017 , in terms of the ratio of absolute and relative volume, increased too fast compared to previous years, and the throughput of Pakistan's ports in the first half of 2018 did not exceed 40 million tons, namely It did not reach $50 \%$ of 2016 . It is inferred that the port throughput in 2017 is an abnormal value. According to the forecast results, the throughput of Pakistan's ports is expected to reach 113 million tons by 2035, an increase of 
Multi-Model Intelligent Prediction of Pakistan Port Throughput under the Background of China-Pakistan Economic Corridor

$10 \%$ over 2017.

\section{Logistic model}

According to the regression of the 1996-2017 time series model, the model results obtained with high goodness of fit are as follows:

$$
\mathrm{Y}=1 /(1 / 0.000032+(0.952687 * * \mathrm{t}))) \mathrm{R} 2=0.941
$$

Table 3 Pakistan port throughput (unit: 100,000 tons) forecast results

\begin{tabular}{c|c|c|c|c|c|c|c}
\hline years & $\begin{array}{c}\text { Port } \\
\text { throughp } \\
\text { ut }\end{array}$ & fitted value & $\begin{array}{c}\text { Error } \\
\text { ratio }\end{array}$ & years & $\begin{array}{c}\text { Port } \\
\text { throughp } \\
\text { ut }\end{array}$ & fitted value & $\begin{array}{l}\text { Error } \\
\text { ratio }\end{array}$ \\
\hline 1996 & 340.6 & 329.800 & $3.17 \%$ & 2010 & 674.27 & 650.023 & $3.60 \%$ \\
\hline 1997 & 359.35 & 346.178 & $3.67 \%$ & 2011 & 613.51 & 682.302 & $-11.21 \%$ \\
\hline 1998 & 357.98 & 363.369 & $-1.51 \%$ & 2012 & 636.9 & 716.185 & $-12.45 \%$ \\
\hline 1999 & 361.9 & 381.413 & $-5.39 \%$ & 2013 & 671.01 & 751.750 & $-12.03 \%$ \\
\hline 2000 & 380.62 & 400.354 & $-5.18 \%$ & 2014 & 709.41 & 789.082 & $-11.23 \%$ \\
\hline 2001 & 399.18 & 420.236 & $-5.27 \%$ & 2015 & 832.18 & 828.267 & $0.47 \%$ \\
\hline 2002 & 412.03 & 441.104 & $-7.06 \%$ & 2016 & 898.51 & 869.398 & $3.24 \%$ \\
\hline 2003 & 432.65 & 463.009 & $-7.02 \%$ & 2017 & 1002.4 & 912.571 & $8.96 \%$ \\
\hline 2004 & 498.94 & 486.002 & $2.59 \%$ & 2020 & & 1055.377 & \\
\hline 2005 & 558.55 & 510.137 & $8.67 \%$ & 2025 & & $1,344.754$ & \\
\hline 2006 & 570.97 & 535.470 & $6.22 \%$ & 2030 & & $1,713.463$ & \\
\hline 2007 & 647.61 & 562.061 & $13.21 \%$ & 2035 & & $2,183.245$ & \\
\hline 2008 & 650.87 & 589.972 & $9.36 \%$ & & & & \\
\hline 2009 & 677.79 & 619.270 & $8.63 \%$ & & & & \\
\hline
\end{tabular}

It can be seen from the error ratio between the actual value of the port throughput and the fitted value that the Logistic model has a lower degree of fit than the neural model, and the error ratio of different years has a large gap. A few years have a higher degree of fit. In 15 years, the error ratio is below $10 \%$, which can be used as a rough reference.

\section{B. Forecast of container throughput}

\section{Neural network prediction}

Uses the neural network method to predict. The GDP, total import and export volume of goods, total population, and the total consumption of residents priced in US dollars at constant prices in 2010 are used as covariates. 1996 From 2016 to 2016, the port throughput (ten thousand TEU) was subjected to machine learning, and the final fitting results are as follows:

Table 4 Pakistan container throughput (unit:ten thousand TEU) forecast results

\begin{tabular}{c|c|c|c}
\hline years & $\begin{array}{c}\text { TEU (ten } \\
\text { thousand } \\
\text { pieces) }\end{array}$ & $\begin{array}{c}\text { Predictive } \\
\text { value }\end{array}$ & Relative error \\
\hline 2003 & 78.76 & 102 & $-29.51 \%$ \\
\hline 2004 & 126.94 & 120.66 & $4.95 \%$ \\
\hline 2005 & 168.64 & 153.48 & $8.99 \%$ \\
\hline 2006 & 177.69 & 166.26 & $6.43 \%$ \\
\hline 2007 & 193.59 & 183.31 & $5.31 \%$ \\
\hline
\end{tabular}

\begin{tabular}{l|c|c|c}
\hline 2008 & 193.8 & 195.34 & $-0.79 \%$ \\
\hline 2009 & 205.81 & 197.5 & $4.04 \%$ \\
\hline 2010 & 214.9 & 205.6 & $4.33 \%$ \\
\hline 2011 & 213.2 & 221.73 & $-4.00 \%$ \\
\hline 2012 & 224.4 & 237.02 & $-5.62 \%$ \\
\hline 2013 & 244.5 & 246.5 & $-0.82 \%$ \\
\hline 2014 & 253.46 & 260.43 & $-2.75 \%$ \\
\hline 2015 & 275.56 & 267.52 & $2.92 \%$ \\
\hline 2016 & 264.51 & 270.46 & $-2.25 \%$ \\
\hline 2020 & & 282.36 & \\
\hline 2025 & & 286.36 & \\
\hline 2030 & & 288.25 & \\
\hline 2035 & & 288.99 & \\
\hline
\end{tabular}

The prediction results of port container throughput using neural prediction method show that, except for the error of $29 \%$ in 2003, the error value of the remaining years is basically below $6 \%$, and since 2013 , the relative error is below $3 \%$, and the degree of fit is very high. The forecast results show that by 2035, Pakistan's container throughput is expected to reach 2.89 million 20 -foot standard containers, an increase of only 190,000 from 2016, indicating that the results of the neural forecasting method indicate that the future economic development of Pakistan is still in a slow start stage., So the increase in forecast results is not obvious.

\section{GM(1,1) model prediction}

Due to the unstable exchange rate of the ruble, the legal currency of Pakistan, the total amount of seaborne cargo denominated in rubles cannot reflect the actual total volume of imported goods. Therefore, the port throughput and port throughput weight indicators are used in the gray forecast. The principle of the $\operatorname{GM}(1,1)$ model is to accumulate the original sequence once to make the generated sequence present a certain law, and then establish a first-order linear differential equation to obtain a fitting curve to predict the system.

Table 5 Pakistan port throughput (unit: 100,000 tons)

\begin{tabular}{cccc}
\hline years & $\begin{array}{c}\text { Cargo } \\
\text { throughput } \\
(100,000 \\
\text { tons })\end{array}$ & years & $\begin{array}{c}\text { Cargo } \\
\text { throughput } \\
(100,000 \\
\text { tons })\end{array}$ \\
\hline 1996 & 340.60 & 2006 & 570.97 \\
\hline 1997 & 359.35 & 2007 & 647.61 \\
\hline 1998 & 357.98 & 2008 & 650.87 \\
\hline 1999 & 361.90 & 2009 & 677.79 \\
\hline 2000 & 380.62 & 2010 & 674.27 \\
\hline 2001 & 399.18 & 2011 & 613.51 \\
\hline 2002 & 412.03 & 2012 & 636.90 \\
\hline 2003 & 432.65 & 2013 & 671.01 \\
\hline 2004 & 498.94 & 2014 & 709.41 \\
\hline 2005 & 558.55 & 2015 & 832.18 \\
\hline
\end{tabular}


Table 6 container throughput (unit: 20'TEU million pieces)

\begin{tabular}{cccc}
\hline years & $\begin{array}{c}\text { Container } \\
\text { throughput } \\
\text { (ten } \\
\text { thousand } \\
\text { TEU })\end{array}$ & years & $\begin{array}{c}\text { Container } \\
\text { throughput } \\
\text { (ten } \\
\text { thousand } \\
\text { TEU ) }\end{array}$ \\
\hline 2003 & 78.76 & 2010 & 214.9 \\
\hline 2004 & 126.94 & 2011 & 213.2 \\
\hline 2005 & 168.64 & 2012 & 224.4 \\
\hline 2006 & 177.69 & 2013 & 244.5 \\
\hline 2007 & 193.59 & 2014 & 253.46 \\
\hline 2008 & 193.80 & 2015 & 275.56 \\
\hline 2009 & 205.81 & 2016 & 264.51 \\
\hline
\end{tabular}

The GM(1,1) model is used to predict the total weight of Pakistan's maritime cargo and the port container throughput. The data comes from the Pakistan Statistical Yearbook and the EPS platform. The specific data is shown in the following table. Use models to predict port cargo throughput data from 1996-2015 and 2006-2015 data; predict port container throughput from 2003-2016 data, compare model results, and select the best prediction model, The model prediction results are as follows:

Table 7 Pakistan port container throughput fitting results (unit: ten thousand TEU )

\begin{tabular}{cccc}
\hline years & $\begin{array}{c}\text { Actual } \\
\text { value }\end{array}$ & fitted value & Relative error \\
\hline 2003 & 78.76 & 78.76 & 0.000 \\
\hline 2004 & 126.94 & 156.73 & -0.190 \\
\hline 2005 & 168.64 & 164.44 & 0.026 \\
\hline 2006 & 177.69 & 172.52 & 0.030 \\
\hline 2007 & 193.59 & 181.01 & 0.070 \\
\hline 2008 & 193.80 & 189.91 & 0.020 \\
\hline 2009 & 205.81 & 199.25 & 0.033 \\
\hline 2010 & 214.9 & 209.04 & 0.028 \\
\hline 2011 & 213.2 & 219.32 & -0.028 \\
\hline 2012 & 224.4 & 230.11 & -0.025 \\
\hline 2013 & 244.5 & 241.42 & 0.013 \\
\hline 2014 & 253.46 & 253.29 & 0.001 \\
\hline 2015 & 275.56 & 265.75 & 0.037 \\
\hline 2016 & 264.51 & 278.81 & -0.051 \\
\hline
\end{tabular}
tons)

Table 8 Pakistan port throughput fitting results (unit: 100,000

\begin{tabular}{cccccccc}
\hline years & $\begin{array}{c}\text { Actual } \\
\text { value }\end{array}$ & $\begin{array}{c}\text { fitted } \\
\text { value }\end{array}$ & $\begin{array}{c}\text { Relat } \\
\text { ive } \\
\text { error }\end{array}$ & $\begin{array}{c}\text { year } \\
\mathrm{s}\end{array}$ & $\begin{array}{c}\text { Actual } \\
\text { value }\end{array}$ & $\begin{array}{c}\text { fitted } \\
\text { value }\end{array}$ & $\begin{array}{c}\text { Relati } \\
\text { ve } \\
\text { error }\end{array}$ \\
\hline 1996 & 340.60 & 340.60 & 0.00 & 2007 & 647.61 & 620.89 & 0.04 \\
\hline 1997 & 359.35 & 361.58 & 0.01 & 2008 & 650.87 & 634.82 & 0.02 \\
\hline 1998 & 357.98 & 377.77 & 0.06 & 2009 & 677.79 & 649.06 & 0.04 \\
\hline 1999 & 361.90 & 394.68 & 0.09 & 2010 & 674.27 & 663.62 & 0.02 \\
\hline 2000 & 380.62 & 412.35 & 0.08 & 2011 & 613.51 & 678.50 & 0.11 \\
\hline 2001 & 399.18 & 430.80 & 0.08 & 2012 & 636.90 & 693.72 & 0.09 \\
\hline 2002 & 412.03 & 450.09 & 0.09 & 2013 & 671.01 & 709.28 & 0.06 \\
\hline 2003 & 432.65 & 470.23 & 0.09 & 2014 & 709.41 & 725.19 & 0.02 \\
\hline
\end{tabular}

\begin{tabular}{llllllll}
\hline 2004 & 498.94 & 491.28 & 0.02 & 2015 & 832.18 & 741.46 & 0.11 \\
\hline 2005 & 558.55 & 513.27 & 0.08 & & & & \\
\hline 2006 & 570.97 & 570.97 & 0.00 & & & & \\
\hline
\end{tabular}

It can be seen that the $\operatorname{GM}(1,1)$ model's prediction of container throughput is better than the prediction of port cargo weight. The relative error between the fitted value of the container throughput prediction and the true value fluctuates at the level of $3 \%$, from 2010 to 2014 The degree of annual fitting is getting better and better, the best fitting is $0.1 \%$ in 2014 , and the highest relative error of forecast in the past seven years is 2016, reaching 5\%.

Due to the large amount of container throughput data, the forecast is divided into two parts, one is based on 20 years of data for forecasting, and the other is based on nearly 10 years of data for forecasting. The above table shows the fitting after residual correction. As a result, it can be seen that compared with the container throughput forecast, the prediction fitting effect of cargo weight is not ideal. The average relative error based on 20-year data forecast fluctuates around $8 \%$, and the average error based on the past 10 years is around 5\%. Floating, but the error fluctuates greatly.

Therefore, the $\operatorname{GM}(1,1)$ prediction formula for the container throughput of Pakistan ports is:

$$
\mathrm{X}(1)(\mathrm{k}+1)=3187.46 \mathrm{e} 0.04797 \mathrm{k}-3108.707
$$

The forecast results are as follows:

Table 9 Forecast of container throughput of Pakistan ports (unit: ten thousand TEU)

\begin{tabular}{cccc}
\hline years & $\begin{array}{c}\text { Forecast } \\
\text { value (ten } \\
\text { thousand } \\
\text { TEU })\end{array}$ & $\begin{array}{c}\text { Average annual } \\
\text { growth rate }\end{array}$ & $\begin{array}{c}\text { Forecast value } \\
(100 \text { million } \\
\text { tons })\end{array}$ \\
\hline 2020 & 337.07 & $6.86 \%$ & 1.1258 \\
\hline 2025 & 428.37 & $5.42 \%$ & 1.43 \\
\hline 2030 & 544.39 & $5.42 \%$ & 1.818 \\
\hline 2035 & 691.86 & $5.42 \%$ & 2.311 \\
\hline
\end{tabular}

By 2025, the container throughput of Pakistan's ports is expected to reach 3.37 million TEU, and by 2035, the container throughput of Pakistan's ports is expected to reach 6.92 million TEU, quadrupling the container throughput of 2016.

\section{CONCLUSION}

In summary, this article predicts Pakistan's port throughput and container throughput based on three methods: neural prediction method, logistic curve prediction, and gray prediction method. It uses different logical thinking to analyze and compare the three methods. The forecast method has the lowest forecast 
value of port throughput and container throughput. The forecast in 2035 is only 11.37 million tons and 2.89 million TEU; the logistic model forecast results show that by 2035, Pakistan's port throughput will be higher than 2017 Doubled to around 220 million tons. The gray forecast method shows that Pakistan's container throughput can reach 6.91 million TEU in 2035 .In addition, due to changes in the international situation, the "Afghanistan-Pakistan Transit Trade Agreement" signed by Pakistan and Afghanistan has been implemented. According to the plan, after 2040, the annual import and export goods will reach 400 million tons per year. Most of the goods traded between Afghanistan and Pakistan will be Through the port of Gwadar.

\section{ACKNOWLEDGMENT}

This research was financially supported by the project of National Social Science Fund of China: (No. 18BJY16 8).

\section{REFERENCES}

[1] Zhao Binbin, Liao Huimin. Analysis of development opportunities of Pakistan's coastal ports under the background of China-Pakistan Economic Corridor[J].Transportation Enterprise Management, 2017(6).

[2] Wang Yongjian, Zhou Jinghui, Li Junxing. SWOT analysis and countermeasures for the development of Gwadar Port[J]. China Harbor Construction, 2015(4):72-74.

[3] Zhang Yinyin. The background, significance and challenges of China's management of Gwadar Port in Pakistan[D]. Jinan University, 2014.

[4] Xi Fang, Wang Chao, Li Junxing. SWOT analysis and developmen strategy of Gwadar Port in Pakistan under the "One Belt One Road" strategy[J]. Transportation Enterprise Management, 2017, 32(2):1-3.

[5] Zhang Lijun, Liu Jiajun. Research on the Intrinsic Factors of Coastal Port Throughput[J]. China Water Transport, 2008(9):18-19.

[6] Xu Jianhua, Jiang Yinghui. Analysis of factors affecting the transportation demand of Ningbo Port[J]. Comprehensive Transportation, 2004(5):53-55.

[7] Zhang Ping, Yan Yixin, Xu Changxin. Extraction of internal factors affecting port throughput[J]. China Harbor Construction, 2006(6):70-72

[8] Jiang Jian, Wang Haiyan, Yang Zan. Econometric analysis of container throughput and main influencing factors $[\mathrm{J}]$. Journal of Dalian Maritime University, 2007, 33(1): 83-86.

[9] Li Jing, Lv Jing. Dynamic research on the influence of hinterland economic development on port throughput[J]. Water Transport Engineering, 2007(11):49-51.

[10] Wang Dan, Yang Zan. Analysis of Influencing Factors of Port Throughput[J]. Water Transport Engineering, 2007(1):45-48.

[11] Chen Taotao, Gao Qin. Research on Influencing Factors of Port Container Throughput[J]. Journal of Wuhan University of Technology (Information and Management Engineering Edition), 2008, 30(6):991-994

[12] Lang Yu, Li Peng. On several theoretical issues of economic integration between ports and hinterland $[\mathrm{J}]$. Economic Geography, 2005, 25(6):767-770.

[13] Zhu Jian. Research on the Factors Influencing the Cargo Throughput of China's Coastal Ports Since the Financial Crisis_-Also on the evidence of the transformation of China's economy from external demand to domestic demand[J]. International Business (Journal of University of International Business and Economics), 2011( 3): 16-25.

[14] Serebrisky T, Sarriera JM, Suárez-Alemán A, et al. Exploring the drivers of port efficiency in Latin America and the Caribbean[J]. Transport Policy, 2016, 45:31-45.

[15] Blonigen BA, Wilson W W. New Measures of Port Efficiency Using International Trade Data[J]. Nber Working Papers, 2006.

[16] Liang Liang, Sheng Zhaohan, Xu Nanrong. An improved analytic hierarchy process [J]. Systems Engineering, 1989(3): 5-7.
[17] Ma Yundong, Hu Mingdong. Improved AHP method and its application in multi-objective decision-making[J]. Systems Engineering Theory and Practice, 1997, 17(6):41-45.

[18] Liu Wanli, Lei Zhijun. Research on the Correction Method of Judgment Matrix in AHP[J]. System Engineering Theory and Practice, 1997, 17(6): 31-35.

[19] Wang Xuehua, Qin Xuezhi. Pattern recognition method for the consistency correction of judgment matrix in AHP $[\mathrm{J}]$. System Engineering Theory and Practice, 1997, 17(11):56-59.

[20] Ariel. Delphi forecast of the dry bulk shipping industry in the year 2000[J]. Maritime Policy \& Management, 2006, 16(4):305-336.

[21] Tian Jun, Zhang Pengzhu, Wang Kanliang, et al. Research on expert opinion integration model based on Delphi method[J]. System Engineering Theory and Practice, 2004, 24(1): 57-62.

[22] Liu Jingxue, Chen Xi. Research on Expert Forecast Method Based on Neural Network[J]. Scientific Decision, 2009(11):78-81.

[23] Fung M K. Forecasting Hong Kong's container throughput: an error- correction model[J]. Journal of Forecasting, 2002, 21(1):69-80.

[24] Wu Xiao, Zong Beihua. Nonlinear combined forecasting of port throughput based on support vector machine regression[J]. Journal of Hohai University (Natural Science Edition), 2005, 33(4): 482-484.

[25] Sun Liang, Tan Derong. Establishment and analysis of port cargo throughput forecast model based on conditional expectations[J]. Water Transport Engineering, 2008(11):1-4

[26] Xu Changxin, Yan Yixin, Zhang Ping. Port throughput forecast model based on system dynamics[J]. Water Transport Engineering, 2006(5):26-28.

[27] Liu Yan, Chen Yimei. Application of Grey System Model in Inland River Port Throughput Forecasting[J]. Water Transport Engineering, 2006(4):31-34. [19] Kuang Haibo. Research on China's coastal port throughput forecasting model [J]. J]. Scientific Research Management, 2009, 30(3):187-192.

[28] Lu Bo, Yang Xianfei, Wang Shouyang. Port throughput forecast model based on situational changes[J]. Management Review, 2018(1):195-201.

[29] Rashed Y, Meersman H, Voorde EVD, et al. Short-term forecast of container throughout: An ARIMA-intervention model for the port of Antwerp[J]. Maritime Economics \& Logistics, 2017, 19(4):749 -764.

[30] Chen SH, Chen J N. Forecasting container throughputs at ports using genetic programming $[\mathrm{J}]$. Expert Systems with Applications, 2010, 37(3):2054-2058.

[31] Wei YY, Lam JS L. 80million-twenty-foot-equivalent-unit container port? Sustainability issues inport and coastal development[J]. Ocean \& Coastal Management, 2013, 71(1):13-25.

[32] Xiao Y, Wang S, Liu JJ, et al. Throughput estimation based port development and management policies analysis[J]. Maritime Policy \& Management, 2016, 43(1):84-97.

[33] Liu Binglian. Analysis of the relationship between port and city [J]. Port Economics, 2002(3): 12-14.

[34] Xu Zhengrong, Du Pei. An Empirical Study on the Relationship between Port Economy and Port-Area Economy[J]. Science and Technology Progress and Policy, 2012, 29(23): 39-43.

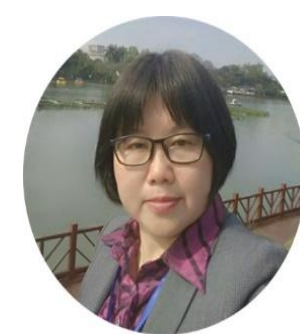

Deng Aimin, Ph.D., Professor of School of Economics and Trade, Hunan University, Ph.D. Supervisor, Director of the Institute of Transportation and Logistics, Hunan University; the first batch of scholars of the Hundred Talents Project of Hunan Province, Director of the Expert Committee / Vice President of Hunan Modern Logistics Society , Expert in the evaluation of master's and doctoral dissertations in the degree center of the Ministry of Education, and expert in reviewing the National Social Science Fund.

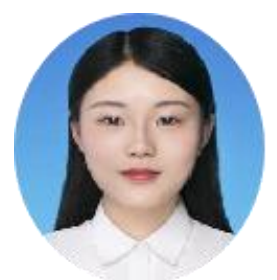

Ding Qian, Master of School of Economics and Trade, Hunan University; Major in Industrial Economics, the research direction is logistics and supply chain management. 